\title{
Predictions of Unsteady Burning of a Fuel Bed
}

\author{
FAN WEICHENG and WANG JIAN
}

Department of Engineering Thermophysics

University of Science and Technology of China

Hefei, Anhui 230026, P.R. China

\section{ABSTRACT}

Unsteady burning of a fuel bed is often encountered in urban and wildland fires. Two kinds of fuel bed are examined. They are a liquid pool and a porous bed. The fuel bed is ig nited at one end by a heat source. The fluid flow, heat and mass transfer, combustion and gasification of the fuel bed, and their interactions in the unsteady burning process of the fuel bed are studied by formulating and solving a set of governing equations.

Additional source terms in the governing equations are proposed to represent the transfer processes of mass, momentum, energy and gasified fuel between solid phase and gas phase of the porous bed. Also, porosity is introduced as a concept and an approach to express the blockage within the porous bed.

Predicted speed of flame spread along the surface of the Heptane pool is around $2 \mathrm{~m} / \mathrm{s}$, which is close to experimental data. Flow field, isotherms and contours of mass fraction of fuel obtained have similar characteristics with typical experimental findings.

KEYWORDS: Fire, Modeling and Simulation.

\section{NOMENCLATURE}

$\begin{array}{llll}\mathrm{A}, \mathrm{B} & \text { constant } & \mathrm{A}_{\mathrm{s}} & \text { constant } \\ \mathrm{C}_{1}, \mathrm{C}_{2} & \text { constant } & \mathrm{C}_{\mathrm{d}} & \text { drag coefficient } \\ \mathrm{C}_{\mathrm{p}} & \text { specific heat } & \mathrm{E} & \text { activation energy } \\ \mathrm{f} & \text { drag force } & \mathrm{g}_{\mathrm{r}} & \text { gravitation constant } \\ \mathrm{H} & \text { combustion heat } & \mathrm{h} & \text { cnthalpy } \\ \mathrm{h}_{\mathrm{in}} & \text { enthalpy of relased gas } & \mathrm{k} & \text { turbulence energy } \\ \mathrm{L} & \text { latent energy } & \mathrm{m} & \text { mass fraction } \\ \dot{\mathrm{m}} & \text { vaporization rate per unit area } & \mathrm{P} & \text { pressure }\end{array}$




$\begin{array}{ll}\mathrm{P}_{\mathrm{o}} & \text { porosity } \\ \mathrm{R} & \text { perfect gas constant } \\ \mathrm{S} & \text { source term } \\ \mathrm{S}_{\mathrm{A}} & \text { upwind arca of wood } \\ \mathrm{T} & \text { temperature } \\ \mathrm{u} & \text { axial velocity } \\ \mathrm{V} & \text { volume } \\ \mathrm{y} & \text { lateral coordinate } \\ \beta & \text { proportional factor } \\ \& & \text { turbulence cnergy dissipation } \\ \Phi & \text { dependent variable } \\ \mu_{\mathrm{eff}} & \text { effective viscosity } \\ \sigma_{\mathrm{h}} & \text { Prandtl number of enthalpy }\end{array}$

$\begin{array}{ll}Q_{t} & \text { heat transfer rate from gas to solid } \\ \dot{R} & \text { chemical reaction rate } \\ \dot{S} & \text { mass flow rate from solid to gas } \\ s & \text { stoichometric ratio of fuel and oxygen } \\ \mathrm{t} & \text { time } \\ \mathrm{v} & \text { lateral velocity } \\ \mathrm{x} & \text { axial coordinate } \\ \alpha & \text { mass fraction in relased gas } \\ \lambda & \text { heat transfer coefficient } \\ \rho & \text { density } \\ \Gamma & \text { exchange coefficient } \\ \mu_{\mathrm{t}} & \text { turbulent viscosity }\end{array}$

\section{Subscripts}

$\begin{array}{llll}\text { fu } & \text { fuel } & \text { ox } & \text { oxygen } \\ \text { pr } & \text { product } & \text { x } & \text { axial coordinate } \\ \text { y } & \text { lateral coordinate } & \text { wo } & \text { wood } \\ \text { e } & \text { east surface of cell } & \text { s } & \text { south surface of cell } \\ \text { w } & \text { west surface of cell } & \text { n } & \text { north surface of cell } \\ \text { v } & \text { volume } & \text { p } & \text { node } \\ \text { क } & \text { dependent variable } & & \end{array}$

\section{INTRODUCTION}

Unsteady burning of a fuel bed is a common phenomenon in both urban and wildland fires. In a wildland fire a tract of woods is simplified as a porous fuel bed. The trees are treated as a solid part of the porous bed, while the air between the trees as a gaseous part of the bed. Thus, the fuel loading and its intervals can be simulated by setting porosity appropriately. In order to understand the mechanism and rules of the phenomenon, the fluid flow, heat and mass transfer, chemical reactions and their interaction in the burning processes must be studied. There have been some works on circular pool fire with the surroundings at rest ${ }^{(1)}$, but no numerical predictions of a fire for a rectangular liquid-pool or a porous fuel bed have been reported in the literature. It would be interesting to see the result, if the processes can be formulated and then solved.

Burning of the two kinds of fuel bed mentioned above is numerically studied, which are sketched in Fig.2. The interaction between the liquid pool and the fire takes place on the surface of the pool, which can be considered through appropriate boundary conditions. For the porous fuel bed the interactions of the bed and fire exist within the bed as well. The influence of the bed on the fire must be taken into account. In the present study this is done by incorporating appropriate source terms into the governing equations of the gas phase, and by introducing volumetric \& surface, porosity in the numerical methods. Source terms added to the continuity, momentum, energy and species equations represent, respectively, the mass transfer from solid to gas, the drag force exerted by the porous surface, the heat transfer from gas to the porous surface, and the production rate of fuel volatiles by pyrolysis. Porosity is a 
mathematical representation of blockage to fluid flow within the region of interest. These will be described in detail in the Section 2. Wind usually affects the fire. The effects are studied here by setting a certain wind speed as a boundary condition of the momentum equation.

\section{MATHEMATICAL DESCRIPTIONS}

\section{A. Governing Equations}

The rectangular fuel bed with infinite length and finite width is placed horizontally. The coming air flows parallel to the fuel bed with an uniform velocity. An ignition source is located at one end of the bed. The main interest in the present study is focused on the unsteady processes between ignition and steady burning. Accordingly, the following assumptions are made:

- the processes are two-dimensional and unsteady;

- the flow and combustion are laminar, if the surrounding air is at rest; the processes will become turbulent, if the coming flow is turbulent or when the flame covers the whole fuel bed;

- the geometry of the fuel bed does not change during the processes studied;

- radiation is negligible, since the flame is small and weak, and the temperature of gas is relatively low during the unsteady processes.

Under these assumptions the governing equations of the gas phase are as follows continuity equation:

$\frac{\partial \rho}{\partial \mathrm{t}}+\frac{\partial(\rho \mathrm{u})}{\partial \mathrm{x}}+\frac{\partial(\rho \mathrm{v})}{\partial \mathrm{y}}=\{\dot{\mathrm{S}}\}$

momentum equation:

$$
\begin{aligned}
& \frac{\partial(\rho u)}{\partial \mathrm{t}}+\frac{\partial(\rho \mathrm{uu})}{\partial \mathrm{x}}+\frac{\partial(\rho \mathrm{uv})}{\partial \mathrm{y}}=-\frac{\partial \mathbf{P}}{\partial \mathrm{x}}+2 \frac{\partial}{\partial \mathrm{x}}\left(\mu_{\mathrm{err}} \frac{\partial \mathrm{u}}{\partial \mathrm{x}}\right)+\frac{\partial}{\partial \mathrm{y}}\left[\mu_{\mathrm{err}}\left(\frac{\partial \mathrm{u}}{\partial \mathrm{y}}+\frac{\partial v}{\partial \mathrm{x}}\right)\right]+ \\
& \left\{\mathrm{u} \dot{\mathrm{S}}-\mathrm{f}_{\mathrm{x}}\right\}
\end{aligned}
$$

$\frac{\partial(\rho \mathrm{v})}{\partial \mathrm{t}}+\frac{\partial(\rho \mathrm{uv})}{\partial \mathrm{x}}+\frac{\partial(\rho \mathrm{vv})}{\partial \mathrm{y}}=-\frac{\partial \mathrm{P}}{\partial \mathrm{y}}+\frac{\partial}{\partial \mathrm{x}}\left[\mu_{\mathrm{efr}}\left(\frac{\partial \mathrm{v}}{\partial \mathrm{x}}+\frac{\partial \mathrm{u}}{\partial \mathrm{y}}\right)\right]+2 \frac{\partial}{\partial \mathrm{y}}\left(\mu_{\mathrm{eff}} \frac{\partial \mathrm{v}}{\partial \mathrm{y}}\right)-\rho \mathrm{g}_{\mathrm{r}}+$

$$
\left\{v \dot{\mathrm{S}}-\mathrm{f}_{\mathrm{y}}\right\}
$$

energy equation:

$\frac{\partial(\rho \mathrm{h})}{\partial \mathrm{t}}+\frac{\partial(\rho \mathrm{uh})}{\partial \mathrm{x}}+\frac{\partial(\rho \mathrm{vh})}{\partial \mathrm{y}}=\frac{\partial}{\partial \mathrm{x}}\left(\Gamma_{\mathrm{h}} \frac{\partial \mathrm{h}}{\partial \mathrm{x}}\right)+\frac{\partial}{\partial \mathrm{y}}\left(\Gamma_{\mathrm{h}} \frac{\partial \mathrm{h}}{\partial \mathrm{y}}\right)+\left\{\mathrm{h}_{\mathrm{in}} \dot{\mathrm{S}}-\mathrm{Q}_{\mathrm{t}}\right\}$

species equation:

$\frac{\partial\left(\rho \mathrm{m}_{\mathrm{fu}}\right)}{\partial \mathrm{t}}+\frac{\partial\left(\rho \mathrm{um}_{\mathrm{fu}}\right)}{\partial \mathrm{x}}+\frac{\partial\left(\rho \mathrm{vm}_{\mathrm{fu}}\right)}{\partial \mathrm{y}}=\frac{\partial}{\partial \mathrm{x}}\left(\Gamma_{\mathrm{fu}} \frac{\partial \mathrm{m}_{\mathrm{fu}}}{\partial \mathrm{x}}\right)+\frac{\partial}{\partial \mathrm{y}}\left(\Gamma_{\mathrm{fu}} \frac{\partial \mathrm{m}_{\mathrm{fu}}}{\partial \mathrm{y}}\right)-\dot{\mathrm{R}}_{\mathrm{fu}}+\left\{\alpha_{\mathrm{fu}} \dot{\mathrm{s}}\right\} \quad(2-5)$

$\frac{\partial\left(\rho \mathrm{m}_{\mathrm{ox}}\right)}{\partial \mathrm{t}}+\frac{\partial\left(\rho \mathrm{um}_{\mathrm{ox}}\right)}{\partial \mathrm{x}}+\frac{\partial\left(\rho \mathrm{vm} \mathrm{m}_{\mathrm{ox}}\right)}{\partial \mathrm{y}}=\frac{\partial}{\partial \mathrm{x}}\left(\Gamma_{\mathrm{ox}} \frac{\partial \mathrm{m}_{\mathrm{ox}}}{\partial \mathrm{x}}\right)+\frac{\partial}{\partial \mathrm{y}}\left(\Gamma_{\mathrm{ox}} \frac{\partial \mathrm{m}_{\mathrm{ox}}}{\partial \mathrm{y}}\right)-\dot{\mathrm{R}}_{\mathrm{ox}}+\left\{\alpha_{\mathrm{ox}} \dot{\mathrm{S}}\right\} \quad(2-6)$ 
where the source terms in brackets, \{\} , are valid only within the porous bed. In the brackets $\dot{S}$ stands for the total mass flow rate from the solid to the gas; $f_{x}$ and $f_{y}$ are drag forces exerted on the gas phase

$\mathrm{f}_{\mathrm{x}}=\mathrm{C}_{\mathrm{dx}} \rho|\mathrm{u}| \mathrm{uS} \mathrm{Ax}_{\mathrm{A}}$

$\mathrm{f}_{\mathrm{y}}=\mathrm{C}_{\mathrm{dy}} \rho|\mathrm{v}| \mathrm{vS} \mathrm{Ay}_{\mathrm{A}}$

where $C_{d x}$ and $C_{d y}$ are drag coefficients; $S_{A x}$ and $S_{A y}$ are upwind areas. $h_{i n}$ refers to the enthalpy of the released gas

$h_{\text {in }}=\alpha_{f_{u}} \mathrm{H}_{\mathrm{fu}}+\mathrm{C}_{\mathrm{p}} \mathrm{T}_{\text {wo }}$

$Q_{t}$ is the heat transfer rate from gas to solid; $\alpha_{f u}$ is mass fraction of species fuei in the released gas.

These governing equations can be written into a general form.

$\frac{\partial(\rho \Phi)}{\partial \mathrm{t}}+\frac{\partial(\rho \mathrm{u} \Phi)}{\partial \mathrm{x}}+\frac{\partial(\rho \mathrm{v} \Phi)}{\partial \mathrm{y}}=\frac{\partial}{\partial \mathrm{x}}\left(\Gamma_{\oplus} \frac{\partial \Phi}{\partial \mathrm{x}}\right)+\frac{\partial}{\partial \mathrm{y}}\left(\Gamma_{\odot} \frac{\partial \Phi}{\partial \mathrm{y}}\right)+\mathbf{S}_{\odot}$

where $\Phi$ stands for dependent variables; $\Gamma_{\Phi}$ for the exchange coefficient and $S_{\Phi}$ for the source term for the appropriate variable $\Phi$.

\section{B. Turbulence Models}

The $k-\varepsilon$ turbulence model with the modifications for buoyancy effects is adopted here for calculation of turbulence viscosity ${ }^{[2]}, \mu_{\mathrm{t}}$.

$\frac{\partial(\rho \mathrm{k})}{\partial \mathrm{t}}+\frac{\partial(\rho \mathrm{uk})}{\partial \mathrm{x}}+\frac{\partial(\rho \mathrm{vk})}{\partial \mathrm{y}}=\frac{\partial}{\partial \mathrm{x}}\left(\Gamma_{\mathrm{k}} \frac{\partial \mathrm{k}}{\partial \mathrm{x}}\right)+\frac{\partial}{\partial \mathrm{y}}\left(\Gamma_{\mathrm{k}} \frac{\partial \mathrm{k}}{\partial \mathrm{y}}\right)+\mathrm{S}_{\mathrm{k}}$

where

$S_{k}=G-\rho \varepsilon$

$\mathrm{G}=\mu_{\mathrm{t}}\left\{2\left[\left(\frac{\partial \mathrm{u}}{\partial \mathrm{x}}\right)^{2}+\left(\frac{\partial \mathrm{v}}{\partial \mathrm{y}}\right)^{2}\right]+\left(\frac{\partial \mathrm{u}}{\partial \mathrm{x}}+\frac{\partial \mathrm{v}}{\partial \mathrm{y}}\right)^{2}-\frac{\beta \mathrm{g}_{\mathrm{r}}}{\mathrm{T} \sigma_{\mathrm{h}}}\left(\frac{\partial \mathrm{T}}{\partial \mathrm{y}}\right)\right\}$

$\frac{\partial(\rho \varepsilon)}{\partial \mathrm{t}}+\frac{\partial(\rho \mathrm{u} \varepsilon)}{\partial \mathrm{x}}+\frac{\partial(\rho \mathrm{v} \varepsilon)}{\partial \mathrm{y}}=\frac{\partial}{\partial \mathrm{x}}\left(\Gamma_{\frac{\partial}{\delta}} \frac{\partial \varepsilon}{\partial \mathrm{x}}\right)+\frac{\partial}{\partial \mathrm{y}}\left(\Gamma_{\delta} \frac{\partial \varepsilon}{\partial \mathrm{y}}\right)+\mathrm{S}_{B}$

where

$\mathrm{S}_{6}=\left(\mathrm{C}_{1} \mathrm{G}-\mathrm{C}_{2} \rho \varepsilon\right) \frac{\varepsilon}{\mathrm{K}}$ 


\section{Models of Turbulent Combustion}

The fuel vopor comes from vaporization of the liquid fuel or pyrolysis of the porous fuel bed. A simple one--step irreversible reaction is used to describe the combustion. A unit mass of fuel combines with $s$ mass units of oxygen to give $(1+s)$ units of products, $s$ here refers to the stoichoimetric ratio of fuel and oxygen.

At the ignition stage temperature and chemical kinetics has a strong effect on the burning process, and so an Arrhenius type of formula of reaction rate is used. Afterward, the mixing processes become more important in controlling the reaction rate. The local reaction rate is expressed with the Magnussen's ${ }^{[3]}$ version of Spalding's eddy-break-up model.

$\dot{\mathrm{R}}_{\mathrm{fu}}=\mathrm{A} \rho \frac{\varepsilon}{\mathrm{k}} \min \left(\mathrm{m}_{\mathrm{fu}}, \frac{\mathrm{m}_{\mathrm{ox}}}{\mathrm{s}}, \frac{\mathrm{m}_{\mathrm{pr}}}{\mathrm{B}(1+\mathrm{s})}\right)$

where $A$ and $B$ are constants given the value 4 and 2 respectively.

\section{Gasification of Fuel}

The liquid fuel surface is placed as the part of one boundary of the integration domain. The motion and variations of temperature within liquid are neglected. The temperature and vaporization rate of the liquid are needed as the boundary conditions of the governing equations of energy and species. The heat feedback to liquid is used for vaporization and rising temperature of the liquid, so we have

$\lambda\left(\mathrm{T}_{1}-\mathrm{T}_{2}\right)=\dot{\mathrm{m}}\left[\mathrm{L}+\mathrm{C}_{\mathrm{p}}\left(\mathrm{T}_{1}-\mathrm{T}_{0}\right)\right]$

and

$\dot{\mathrm{m}}=\mathrm{A}_{\mathrm{s}} \exp \left(-\frac{\mathrm{E}}{\mathrm{RT}}\right)$

where $\lambda$ is a heat transfer coefficient; $T_{2}$ the temperature of the gas adjacent to liquid surface; $T_{1}$ the temperature of liquid related to the vaporization rate, and $T_{0}$ the initial temperature of the liquid; $\dot{m}$ and $L$ stands for vaporization rate per unit area and latent heat respectively.

In the case of the unsteady burning of a porous fuel bed, the porous fuel bed is placed within the system studied. It can not be treated as a boundary. The temperature of the solid part of the porous bed increases as heat is transferred to it from the gas phase. Wood is here taken as the material of the solid part of porous bed. Variation of its pyrolysis rate with its temperature can be found from the literature ${ }^{[4]}$.

$$
\begin{cases}\dot{\mathrm{m}}=4.9 \exp \left(-\frac{779}{\mathrm{~T}_{\mathrm{wo}}}\right) \rho_{\mathrm{wo}} \frac{\mathrm{V}_{\mathrm{wo}}}{\Delta \mathrm{t}} & \left(\mathrm{T}_{\mathrm{wo}}<400 \mathrm{C}^{\circ}\right) \\ \dot{\mathrm{m}}=\left(0.84-\frac{56.4}{\mathrm{~T}_{\mathrm{wo}}}\right) \rho_{\mathrm{wo}} \frac{\mathrm{V}_{\mathrm{wo}}}{\Delta \mathrm{t}} & \left(\mathrm{T}_{\mathrm{wo}} \geqslant 400 \mathrm{C}^{\circ}\right)\end{cases}
$$


where $\rho_{\mathrm{wo}}$ is the density of wood; $T_{\mathrm{wo}}$ is the temperature of wood.

\section{E. Numerical Methods}

The set of governing equation is discretized with the second-order upwind differencing scheme (QUICK) ${ }^{(5)}$, and then solved iteratively with the SIMPLE procedure ${ }^{(6)}$.

In order to compute the unsteady burning of a tract of forest a way is needed to simulate its presence within the integration domain and to account for the interactions between the trees and the gas within or outside the tract of forest. The trees and the gas in between are considered as the solid and the gaseous part of a porous bed respectively. It is not possible to know the details of motion of gas within the porous bed in the small scale because the boundary conditions are two complicated and the number of grid required for resolution are for too big for the present computer, if a forest fire is to be numerically simulated. Therefore, a compromise has to be made between accuracy and practicability. Fortunately, our interest is on the relatively large scale motion from the practical point of view.

Porosity is here proposed as a concept and approach to simulate the porous fuel bed within the integration domain. Porosity is a proportion of a cell through which fluid can flow. Both volume porosity and surface porosity are introduced. They express the proportions of volume and surface of a cell respectively, which are available for fluid flow in the cell. In other words, this part is not blocked. Unity porosity means no blockage, while complete blockage is represented by zero porosity. Porosity can be as factors incorporated into the discretized equations ${ }^{(7)}$,

$\frac{\partial\left(\rho \Phi \mathrm{VP}_{\mathrm{ov}}\right)}{\partial \mathrm{t}}+\sum_{\mathrm{i}}\left[\left(\rho \overrightarrow{\mathrm{U} \Phi}-\Gamma_{\phi} \operatorname{grad} \Phi\right) \overrightarrow{\mathrm{AP}}_{\mathrm{oi}}\right]=\left(\mathrm{S}_{Q} \mathrm{VP}_{\mathrm{ov}}\right)_{\mathrm{p}}$

where $V$ stands for the volume of a cell; $P_{o v}$ and $P_{o i}$ for the volume porosity and surface porosity of the cell respectively; the subscript $\mathrm{i}$ for each surface of the cell. For example, the volume porosity is 0.25 , and the surface porosities $\mathbf{P}_{\text {ow }}, \mathbf{P}_{\text {os }}, \mathbf{P}_{\text {oc }}, \mathbf{P}_{\text {on }}$ are equal to $1 ., 0.5,0.5,1$. respectively in the cell shown in Fig.1.

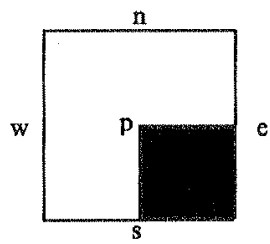

FIGURE 1. Porosities of a cell

All of models and numerical methods described above have been programed as a FAC2 computer code (Fire And Combustion 2-Dimensional), which is taken for the present study. 
Boundary conditions of governing equation are given in Fig.2.

\begin{tabular}{|c|c|c|}
\hline $\begin{array}{l}\frac{\partial \mathrm{u}}{\partial \mathrm{x}}=\frac{\partial \mathrm{v}}{\partial \mathrm{x}}=0 \\
\frac{\partial \mathrm{k}}{\partial \mathrm{x}}=\frac{\partial \mathrm{s}}{\partial \mathrm{x}}=0 \\
\text { if } \mathrm{u} \geqslant 0 \\
\mathrm{f}=0, \mathrm{~m}_{\mathrm{ox}}=0.232 \\
\mathrm{~m}_{\mathrm{fu}}=0, \mathrm{~h}=\mathrm{h}_{\mathrm{air}} \\
\text { if } \mathrm{u}<0 \\
\frac{\partial \mathrm{h}}{-}=\frac{\partial \mathrm{f}}{}=\frac{\partial \mathrm{m}_{\mathrm{fu}}}{}=0\end{array}$ & 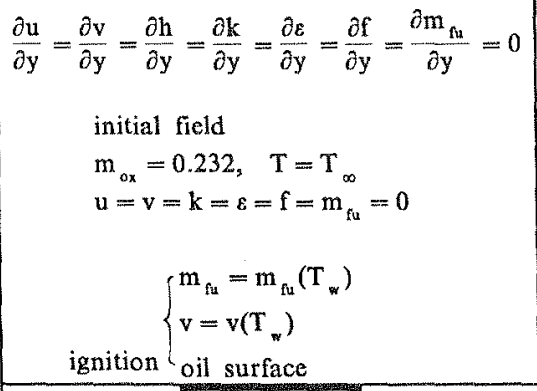 & $\begin{array}{l}\text { if } \mathrm{u} \leqslant 0 \\
\mathrm{f}=0, \mathrm{~m}_{\text {ox }}=0.232 \\
\mathrm{~m}_{\mathrm{fu}}=0, \mathrm{~h}=\mathrm{h}_{\text {air }} \\
\text { if } \mathrm{u}>0 \\
\frac{\partial \mathrm{h}}{\partial \mathrm{x}}=\frac{\partial \mathrm{f}}{\partial \mathrm{x}}=\frac{\partial \mathrm{m}_{\mathrm{fu}}}{\partial \mathrm{x}}=0 \\
(1) \text { wall } \\
\mathrm{u}=\mathrm{v}=\mathrm{k}=\varepsilon=0 \\
\frac{\partial \mathrm{h}}{\partial \mathrm{y}}=\frac{\partial \mathrm{f}}{\partial \mathrm{y}}=\frac{\partial \mathrm{m}_{\mathrm{fu}}}{\partial \mathrm{y}}=0\end{array}$ \\
\hline $\bar{x}=\overline{\partial x}=\overline{\partial x}$ & 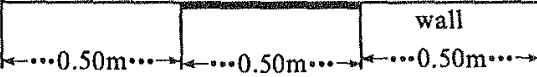 & $\begin{array}{l}\text { (2) oil surface } \\
\mathrm{u}=\mathrm{k}=\varepsilon=0\end{array}$ \\
\hline
\end{tabular}

$$
\begin{aligned}
& \frac{\partial \mathrm{v}}{\partial \mathrm{x}}=\frac{\partial \mathrm{k}}{\partial \mathrm{x}}=\frac{\partial \varepsilon}{\partial \mathrm{x}}=0 \\
& \mathrm{u}=0.5 \mathrm{~m} / \mathrm{s} \\
& \mathrm{f}=0, \mathrm{~m}_{\alpha \mathrm{x}}=0.232 \\
& \mathrm{~m}_{\mathrm{fu}}=0, \mathrm{~h}=\mathrm{h}_{\text {air }}
\end{aligned}
$$

(1) wall $\mathrm{u}=\mathrm{v}=\mathrm{k}=\varepsilon=0$ $\frac{\partial \mathrm{h}}{\partial \mathrm{y}}=\frac{\partial \mathrm{f}}{\partial \mathrm{y}}=\frac{\partial \mathrm{m}_{\mathrm{fu}}}{\partial \mathrm{y}}=0$

$$
\frac{\partial \mathrm{u}}{\partial \mathrm{x}}=\frac{\partial \mathrm{v}}{\partial \mathrm{x}}=0
$$$$
\text { if } \mathrm{u} \leqslant 0
$$$$
\mathrm{f}=0, \mathrm{~m}_{\alpha \mathrm{x}}=0.232
$$$$
\mathrm{m}_{\mathrm{fu}}=0, \mathrm{~h}=\mathrm{h}_{\mathrm{air}}
$$

if $u>0$

$\frac{\partial \mathrm{h}}{\partial \mathrm{x}}=\frac{\partial \mathrm{f}}{\partial \mathrm{x}}=\frac{\partial \mathrm{m}_{\mathrm{fu}}}{\partial \mathrm{x}}=0$

ignition

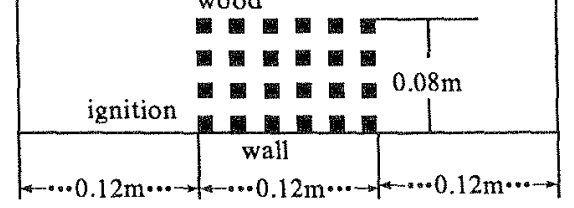

FIGURE 2. Boundary condition for unsteady burning of a liquid pool (above) and a porous bed (below)

Most of calculations were performed with the IBM PC/AT, and the typical results are given below.

\section{RESULTS AND DISCUSSION}

\section{A. Unsteady Burning of Liquid Pool}

Computational results for unsteady burning of a Heptane pool with width equal to $0.5 \mathrm{~m}$ are shown in Fig.3. 




(a)

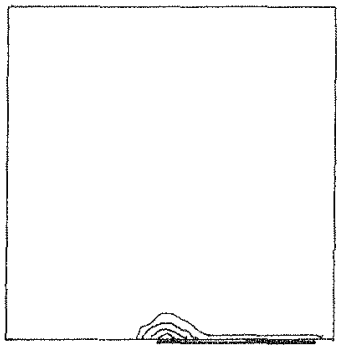

(d)

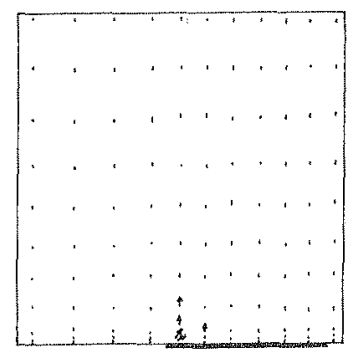

(g)

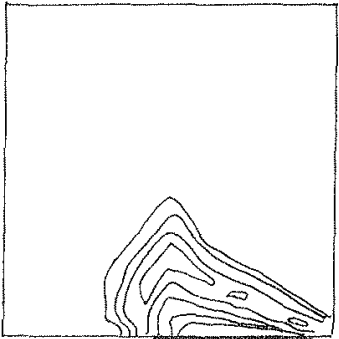

(b)

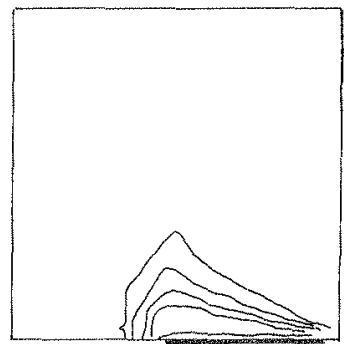

(e)

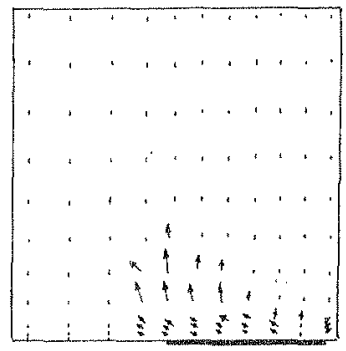

(h)

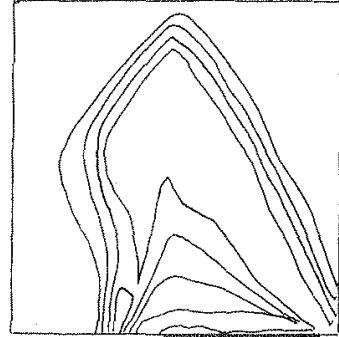

(c)

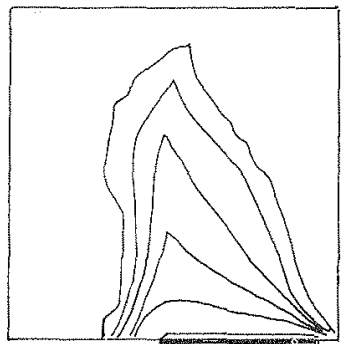

(f)



(i)

FIGURE 3. Predictions of burning of a heptane pool

The isotherms are given in Fig. 3 (a), (b) and (c), corresponding to $0.1,0.25$ and 0.5 second after ignition respectively. The corresponding contours of fuel mass fraction and flow pattern are shown in (d), (c), (f) and (g), (h), (i). It can be secn that the flame spreads from the ignition source along the surface of the liquid pool to the other end of the pool. It is found from the figure that the flame spreads to cover the whole surface of the pool $0.5 \mathrm{~m}$ in width in 0.25 second. Therefore the predicted speed of flame spread on average is around $2 \mathrm{~m} / \mathrm{s}$, which is in agreement with experiment findings to some extent. Also, it is noted that the flow is induced by buoyancy due to the heat release in the combustion process. The induced flow enhances heat and mass transfer by convection and mixing, and intensifies the burning. Half a second after ignition, see Fig. 3 (i), a rather large fire is formed, and the entrainment from environment to the fire plume is much stronger than before, and the recirculating flow can be seen in the downright part of the integration domain. 


\section{B. Unsteady Burning of A Porous Fuel Bed}

The porous fuel bed is $0.12 \mathrm{~m}$ wide and $0.08 \mathrm{~m}$ high, occupying $6 \times 4$ cells in the integration domain. The porosity of the bed is supposed to be uniform. For each cell in the bed, its volume porosity is 0.25 , and the surface porosity are $1 ., 0.5,0.5$, and 1 . respectively for the west, south, east and north surface of the cell. The ignition source of $500 \mathrm{~W}$ is located in the downright corner of the bed, and occupies two cells there. Airflow comes into the integration domain from its east boundary with the uniform velocity of $0.5 \mathrm{~m} / \mathrm{s}$.

Many computations have been performed, but only some typical results are given here. Fig.4 shows the flow field at a time 10 second after ignition. It is seen clearly that there is a flow upward driven by buoyancy near the heat source within the porous bed.

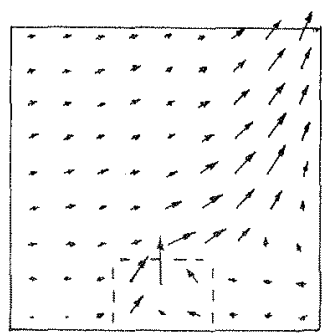

FIGURE 4. Velocity field of burning of a porous bed

The flow field, isotherms and contours of mass fraction of gas-fuel at a moment $12 \mathrm{sec}-$ ond after ignition are shown in Figs 5 (a), (b), and (c), respectively. The flow pattern is different in scale of velocity vector with that show in Fig.4, which can be seen by reference to the scale of the incoming velocity. The flame zone is located above the porous bed, and has typical shape of a fire in a cross flow field, which is indicated by the isotherms. It is found by inspection of Fig. 5 (c), that the mass fraction of fuel volatile reaches its maximum in the region above the ignition source. The major part of the region is within the porous bed. Therefore, it would not be justified if the porous fuel bed is simply treated as a solid fuel.

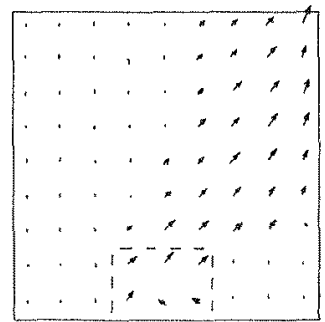

(a)

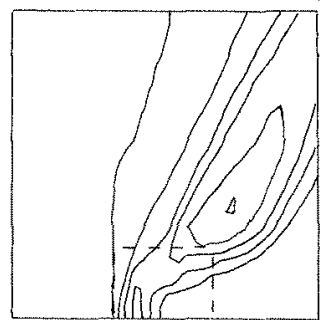

(b)

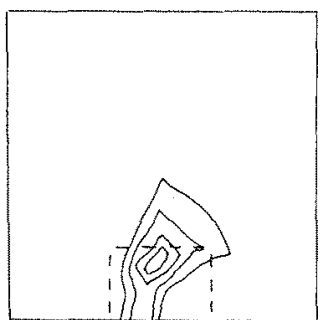

(c)

FIGURE 5. Velocity, isotherms and contours of mass fraction of fuel in burning of a porous bed 12 seconds after ignition 
Discrepancy between the predictions and a real fire may result from neglecting some subprocesses, such as radiation, soot formation and consumption, motion within the liquid, and heat transfer in the solid part of the porous bed. These will be accounted for in the ongoing project.

\section{CONCLUSTONS}

Unsteady burning of a combustible-liquid pool and a porous fuel bed with a cross airflow have been predicted respectively. The computational results obtained are plausible and promising. The burning of a porous fuel bed is different from that of a solid one due to the existence of gas flow, convective heat transfer, combustion, and their interactions within the bed. The processes can be studied by constructing and solving a set of governing equations of gas phase with appropriate modifications of their source terms and numerical treatment of introducing volumetric and surface porosity of each cell into the discretized equations.

Both models and numerical methods adopted for calculations need to be verified by comparisons with experimented data. Therefore, experimental studies on unsteady burning of a fucl bed with a cross airflow are required and appreciated.

\section{REFERENCES}

1. Delichatsios, M.A., "Air entrainment in buoyant jet flames and pool fires", Combustion and Flame, 70: 1, 33-46, 1987.

2. Rodi, W., Turbulence buoyant jets and plumes, Pergamon, Oxford, 1982.

3. Magnussen, B.F., and Hjertager, B.H., "On mathematical modeling of turbulent combustion with special emphasis on soot formation and combustion", 16th Symposium (International) on Combustion, pp. 711-729, Pittsburgh, Pa., The Combustion Institute, 1976.

4. Kawagoe, K. etc., Defence of Building Fires, Industrial Investigation Institute, Tokyo, 1980. (in Japanese)

5. Leonard, B.P., "A stable and accurate convective modeling procedure based on quadratic upstream interpolation", Computer methods in applied mechanics and engineering, 19:1, $59-98,1979$.

6. Patankar, S.V., and Spalding, D.B., "A calculation procedure for heat, mass and momentum transfer in 3-dimensional parabolic flows", International Journal of Heat and Mass Transfer, 15: 9, 1787-1806, 1972.

7. Fan, W.C., "Porosity and its application in the computational fluid dynamics", Journal of China USTC, 15: 4, 460-464, 1985. (in Chinese) 